\title{
Maintaining numerical stability of flood plain calculations by time increment splitting
}

Proc. Instn Civ. Engrs Wat., Marit. \& Energy, 1992, 96, Dec., 269

Paper 9806

\author{
G. Pender
}

Dr W. L. Wood, Department of Mathematics, University of Reading Oscillation with iteration often indicates that some form of under-relaxation (damping) is needed. It would be interesting to compare the cost-efficiency for the solution of the flood plain problem of the method described by Dr Pender with the method used by Connorton and Wood ${ }^{10}$ for reducing oscillation in the solution of the equations representing groundwater flow in the presence of ephemeral streams. The corresponding steps here would be to calculate $H_{p}^{n+1(k)}$ by using $\frac{1}{2}\left(H_{\mathrm{p}}^{n}+H_{\mathrm{p}}^{n+1(k-1)}\right)$, and to insert this at the step in the flow chart where the reversal of the water level gradient over the embankment is first encountered, rather than reducing the pond time step size here. There is an averaging step later in the flow chart, but is this ever implemented?

\section{Dr Pender}

Dr Wood is quite correct in stating that damping will aid in the control of flood plain oscillations. The insertion of the suggested averaging procedure into the algorithm will undoubtedly improve computational efficiency for some flood plain configurations. However, in my experience, it is always possible to generate some realistic combination of flood plain geometry and lateral flow relationships that results in unstable behaviour when averaging procedures alone are adopted.

26. The averaging procedure indicated in the flow chart overcomes the convergence failure found to occur during testing of the algorithm when

$$
H_{\mathrm{p}}^{n+1(k)}=H_{\mathrm{p}}^{n+1(k+2)}
$$

and

$$
H_{\mathrm{p}}^{n+1(k+1)}=H_{\mathrm{p}}^{n+1(k+3)}
$$

\section{Reference}

10. Connorton B. J. and Wood W. L. Noise problems with ephemeral streams in aquifer models. Int.J. Num. Meth. in Fluids, 1983, 3, 201-208.
Paper published: Proc. Instn Civ. Engrs Wat., Marit. \& Energy, 1992, 96, Mar., $35-42$ 